\title{
El Año Internacional de la Economía Creativa inaugura la era $\mathrm{Z}$
}

The International Year of Creative Economy

Inaugurates the $Z$ Era

\author{
Xavier Ferrer i Serra \\ Director de Creabinars.org, \\ bub creativo digital
}

Podemos afirmar, sin temer a equivocarnos que el año de la pandemia, el periodo que va desde marzo de 2020 hasta el momento en el que redacto estas líneas, justo un año después, ha sido sin duda, como ha dicho, con cierta ironía Christien Bok, el año en el que hemos pasado del 2020 al 2030, en un fin de semana.

Son tantos los impactos, de tanta profundidad y tan disruptivos en el sector de las industrias creativas y culturales que cuesta hacerse una idea.

Algunos de esos impactos a los que aludo, los he tenido que experimentar y conocer en primera persona, puesto que mi labor como gestor cultural ha pasado del área analógica al área digital casi completamente y fruto de esa evolución nació Creabinars.org, el primer bub creativo virtual, especializado en consultoría para los nuevos modelos de negocio cultural, la transformación digital y la generación de contenidos de valor especializados en las industrias culturales y creativas. 
En este periodo, por citar alguna de las muchas actividades que realizamos, tuve la ocasión de entrevistar para Creabinars.org a Mónica Ramírez Hartmann, directora de CoCrea Colombia, una organización mixta creada por el impulso del gobierno colombiano y de la sociedad civil, con el fin de atajar el problema de la deficiente y endémica financiación de las industrias creativas y culturales, a través de la puesta en marcha de un novedoso mecanismo de mecenazgo fiscal y administrativo.

La entrevista tuvo un sabor agridulce por que por un lado, pudimos contar que por fin se pone en marcha un modelo de financiación eficaz para nuestro sector y por otro, salió a colación en el preludio de la conversación, el nefasto efecto que ha causado la pandemia sobre las ya frágiles texturas de nuestras industrias, efecto que ha hecho retroceder económicamente al menos una década a todo el sector, situación común a todas las geografías.

Además no solo ha sido un año con un grave impacto económico, sino también ontológico, ha sido el año en el que estalló la cultura analógica e industrial en pedazos y se alumbró de manera irreversible, la cultura digital posindustrial. Una flamante cultura que balbucea, con nuevos vocablos en inglés: streaming, transmedia, AI, bubs, shopable ads, VR, Video OTT, metaverse, NFT o blockchain, por ejemplo, son algunos de los incorporara a nuestra habitual y cotidiana jerga, esta nueva mutación digital, que hemos engendrado.

Para muchos profesionales de la cultura, es como si (voy a usar alguna metáfora), en mitad de una partida de ajedrez se presentara un ángel exterminador, y su devastador efecto fuese que el color del damero súbitamente cambiara, las fichas se desvanecieran y las reglas de juego fueran otras, sin que se hubieran revelado las nuevas reglas.

Muy a su pesar, a cambio vivimos un momento de incertidumbre en la que tenemos que ir descubriendo e improvisando 
todo sobre la marcha. La consecuencia, es que solo de nuestra audacia al innovar, de ensayar y de rectificar los nuevos códigos y protocolos, depende el éxito de la partida.

Tan disruptiva es la omnipresencia de lo digital para el sector de las industrias culturales y creativas que los patrones de consumo, la producción de los activos y su distribución, han transformado los modelos de negocio cultural y han diversificado los agentes con la irrupción de nuevos canales, redes y modelos de creación.

Pongamos algunos ejemplos: los canales clásicos como galerías o ferias son sustituidos por marketplaces virtuales cotizados en criptomonedas, los infoproductos, una industria global floreciente a mitad de camino entre la educación y los contenidos producidos por los media golpean al sistema educativo pre digital, la audio visualización de las instituciones culturales se convierte en una condición básica para su supervivencia, las nuevas aplicaciones ejercen de intermediario entre productores de contenidos y plataformas o broadcasters clásicos o las cadenas de autentificación a través de blockchain hacen emerger prometedores mercados de activos no cotizados hasta la fecha.

Algunos ya se atreven a denominar esta nueva variante como criptocultura, una nueva frontera, que permite singularizar firma y título de propiedad de cualquier tipo de creación digital, que hasta ahora era accesible para cualquiera y reproducible sin ningún tipo de control y que ha creado un mercado cotizado en criptodivisas de dimensiones multimillonarias del día a la noche.

Hace un par de semanas, la casa de subastas Christhie's abrió la veda con la venta por 58,8 millones de euros del collage de 5000 imágenes que Beeple tituló Everydays: the first 5000 days, un parteaguas que rompe radicalmente con la tradición de la casa respecto a los productos subastados, la trazabilidad de la provenance de la obra o la misma estructura del mercado del arte. 


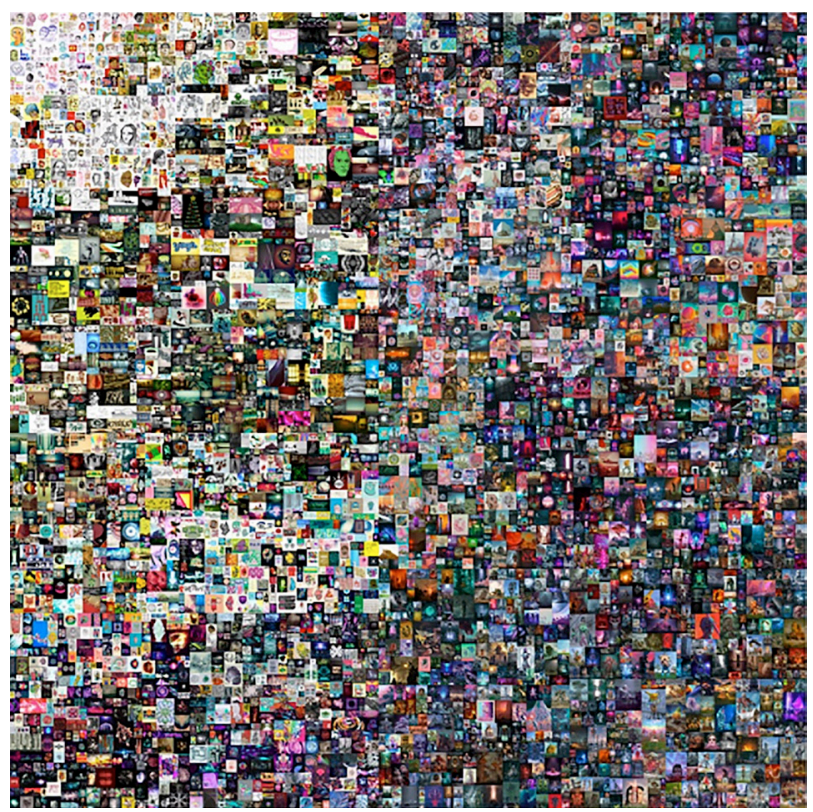

Figura 1. Everydays: The first 5000 days, obra de Beeple.

Fuente: https://onlineonly.christies.com/s/beeple-first-5000-days/beeple-b-1981-1/112924.

Como afirma el abogado especialista en blockchain Joaquim Matinero Tor, «Ahora los galeristas y mecenas ya no son tan necesarios. Con la certificación de propiedad de los NFT y los contratos que permiten las ventas directas y seguras, los artistas pueden tener un mayor control de las obras». Todo un terremoto en el epicentro de nuestros sistemas culturales todavía analógicos.

Considero que todos estos cambios que describo, tienen una raíz tecnológica pero simultáneamente, son socioeconómicos y están empujados por un cambio de valores generacional, y esto es quizá lo más significativo. Se ha configurado una nueva «Era Z» cuya comprensión y efectos deben ser reconocidos, evaluados y monitorizados a la luz de los acontecimientos promovidos por la primera generación nativa digital, la generación Z. 
Generación que a través de encuestas y entrevistas, como la recientemente publicada por Spotify, sobre los cambios globales en la cultura, revela una actitud de reconstrucción y deconstrucción social y económica, desde la base hacia la cima.

Aprovechando esto, en Creabinars.org, hace unos meses realizamos un estudio cuyas conclusiones, hoy les comparto sobre las tendencias globales de la cultura digital, enfocados muy especialmente en la generación nacida digital, abanderada de una revolución de dimensiones tan gigantescas como pudo ser la invención de la imprenta.

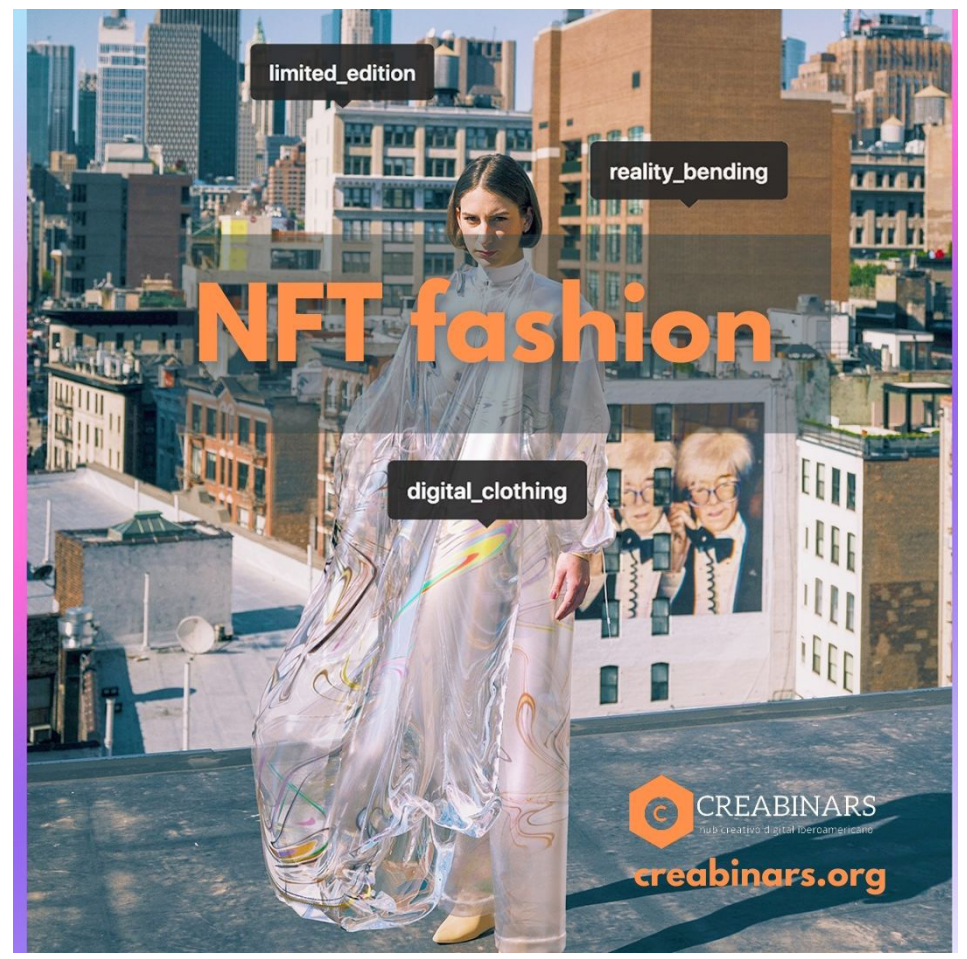

Figura 2. The Fabricant realizó hace unos días el primer vestido digital vendido a través de NFT. 
Estos son los rasgos que podemos encontrar y que abren un parteaguas en nuestro horizonte actual y futuro:

\section{Cultura DIY, bágalo Vd. mismo}

Para los jóvenes que han crecido con internet, el conocimiento se ha hecho plano, sin jerarquías ni compartimentos. Su personalidad está siendo conformada en una sociedad líquida donde el conocimiento es abierto, descentralizado, comunitario y autodidacta.

Esta tendencia aparece claramente en uno de los estudios mencionados anteriormente el de Spotify, en el que casi la mitad de $\operatorname{los} Z$ que fueron entrevistados en 2019, dijeron que las generaciones mayores, no pueden actuar como guía en este momento, porque el mundo ha cambiado demasiado, y esto fue antes de los grandes cambios de 2020. En la encuesta de julio de 2020, ese número se elevó a un $67 \%$.

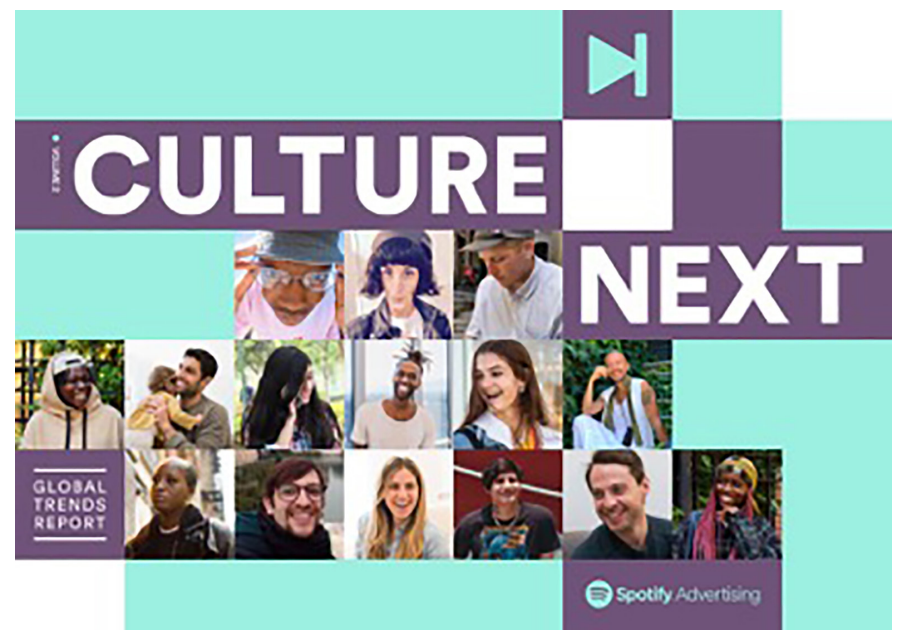

Figura 3. Estudio de Spotify sobre tendencias y comportamientos culturales de la generación Z. Fuente: https://culturenext.byspotify.com. 
Esto hace que introduzcan una fuerte crítica al sistema educativo actual «La visión del mundo que nos ofrece la escuela no tiene una correlación aparente con lo que vemos y necesitamos hoy», afirman.

Esto convierte a la generación $\mathrm{Z}$ en autodidactas. El 33\% aprende vía tutoriales en internet. Más del $20 \%$ lee solo en tablets y dispositivos, y el $32 \%$ hace todas sus tareas y labores online. $\mathrm{Na}-$ cieron con la cultura do it yourself, así que están acostumbrados a solucionar problemas y necesidades de manera personal y enfocada. El acceso a internet les ha dado las herramientas necesarias para encontrar la manera de construir su propio mundo.

Las recomendaciones de manos de los expertos, van en la línea de reiniciar el proceso educativo para reconectar la sociedad con las instituciones educativas, de modo que sean útiles para las generaciones nativas digitales y funcionales en los ecosistemas de innovación.

En este sentido la Fundación española para la innovación COTEC, afirma en su decálogo para reiniciar la Universidad que es necesario integrar en los procesos educativos universitarios los diferentes contextos formativos - formal, no formal e informal-; además de combinarlos con la capacidad autodidacta, que crece día a día gracias al acceso a la información y al conocimiento que proporciona la tecnología. En paralelo, deben crearse canales de comunicación y trabajo en equipo que conecten entre sí a las diferentes etapas del sistema educativo formal, prestando una especial atención a la relación entre formación profesional y universidad.

\section{Las redes, principio de todas las cosas}

Los miembros de la generación $\mathrm{Z}$ han hecho del uso masivo de las redes sociales su seña de identidad. De esta forma, cada 
vez tienen más oportunidades de colaborar en proyectos culturales, sociales, políticos y empresariales, así como de expresar su creatividad con menos esfuerzo.

Pero este concepto de socialización, también supone un reto para esta generación, que deberá saber equilibrar su vida real y «cibernética», así como lidiar con el riesgo de adicción tecnológica y otros peligros relacionados con la privacidad, el acoso y el cibercrimen.

De hecho, las plataformas tecnológicas, no solo brindan la oportunidad de descubrir cosas, también permiten que los Z colaboren, creen y compartan, vendan, y promuevan su trabajo.

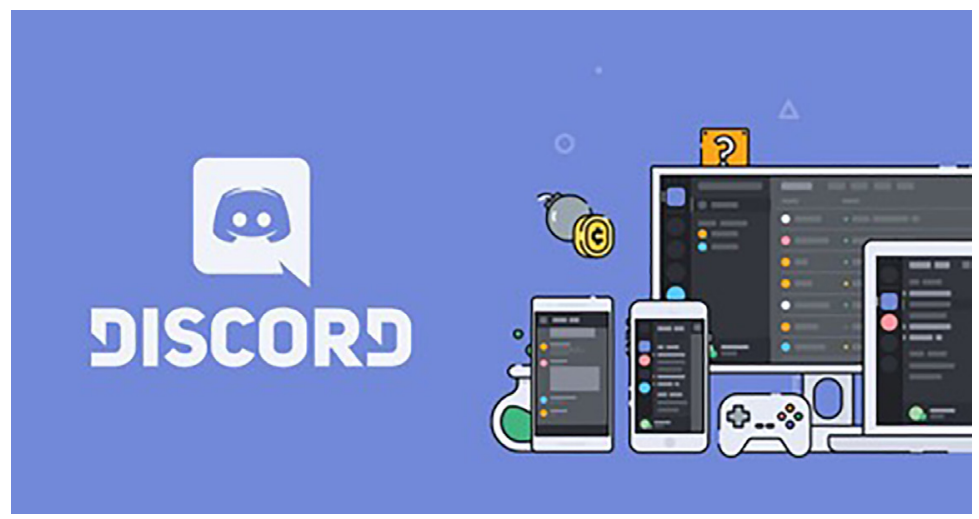

Figura 4. Discord es una plataforma que permite crear servidores de chat con los que los usuarios aficionados a una temática concreta pueden reunirse.

Esta idea de autodescubrimiento no es exclusivo de los $\mathrm{Z}$ y los millennials, pero tiene un aspecto diferente gracias al acceso y el crecimiento de la oferta en tecnologías de la conectividad.

A través de su investigación, Spotify descubrió que los jóvenes se forman cada vez más identidades basadas en intereses específicos, y se vinculan con otros que comparten esos mismos 
intereses en todo el mundo: el $70 \%$ de los estadounidenses $\mathrm{Z}$ y los millennials, dijeron que es mucho más fácil sentirse conectado a una comunidad hoy gracias a las plataformas digitales. Cuando se les preguntó sobre los elementos que alimentan su autodescubrimiento, el $76 \%$ citó la música y $68 \%$ citó los podcasts.

Lo que es común a todos ellos es que en este momento, gracias a las redes, muchos pueden convertir con más facilidad sus pasiones en carreras creativas, saltando pasos, barreras de entrada y procesos para los que, sin las herramientas tecnológicas antes era casi imposible.

La constante floración de nuevos creadores, la construcción de comunidades planetarias basadas en nuevos gustos o tendencias, la facilidad de acceso al consumidor potencial y su desinhibida transdisciplinariedad, han hecho revivir la idea de un «Nuevo Renacimiento».

\section{Autonomía laboral}

La generación Z es la generación de las startups: buscan, principalmente, desarrollar emprendimientos sociales que promuevan un cambio, que impacte positivamente en la comunidad.

Como afirma Deep Pattel uno de los estrategas de marketing más reconocidos en el mundo digital, «Este nuevo mundo en desarrollo que combina alta tecnología e hiperconectividad, ha dado como resultado que toda una generación piense y actúe de manera más emprendedora».

Para triunfar, confían en su «red» de contactos antes que en los diplomas, y prefieren una organización horizontal comunitaria, antes que una jerárquica.

Los jóvenes de esta generación valoran el dinero, pero valoran todavía más los buenos proyectos, por lo que si se comprometen con uno realmente, son entusiastas. 
Según un informe de Deusto Business School, que recogimos para redactar estas conclusiones, a los jóvenes $Z$, les preocupa mucho no encontrar un empleo acorde a su personalidad, no tener oportunidades de crecimiento profesional y no alcanzar las metas que se marquen a lo largo de su carrera, mas que la recompensa económica.

Asimismo, prefieren entornos flexibles que faciliten la conciliación de su vida profesional y personal, así como que favorezcan su creatividad.

Por otro lado, la generación Z, acentúa las particularidades de los millennials, pues su preferencia por la autonomía en el entorno laboral, fuerza a las empresas a proporcionarles una esfera de libertad en la que se alineen sus intereses con los de la organización.

Además, estos jóvenes acostumbrados a la inmediatez y eficiencia que proporciona la tecnología incrementan la presión de las empresas por revisar sus procedimientos internos e invertir en su mejora.

Por último, las nuevas generaciones serán protagonistas de la llamada gig economy, es decir, una gran red de trabajados autónomos que, enlazados en cadena, generan un gran proyecto. Una parte de los jóvenes $Z$ se acostumbrará a vincularse a proyectos más que a empleadores, lo que proporcionará mayores cotas de independencia, aunque también incrementará la incertidumbre y el riesgo de caer en la precariedad laboral.

\section{Espacio físico, espacio virtual}

Tanto los millennials como los miembros de la generación $\mathrm{Z}$ son las primeras generaciones más interesadas en las experiencias que en adquirir más «cosas», importando estas, más que la marca o el producto. 
Según la firma consultora Touchstone Research «La realidad virtual se está convirtiendo en una experiencia única. En su mejor iteración, permite a los consumidores acceder a un mundo al que probablemente no irían de otra manera. Les conecta e inspira a sumergirse en un nuevo universo creativo. Aunque la generación $\mathrm{Z}$ aprecie las botas vintage o una chaqueta de bombardero de la guerra de Vietnam que le haya pasado su abuelo, también aprecia las experiencias memorables y exóticas. Cuanto más memorable sea la experiencia, más probable será que los miembros de la generación Z la compartan con sus círculos sociales».

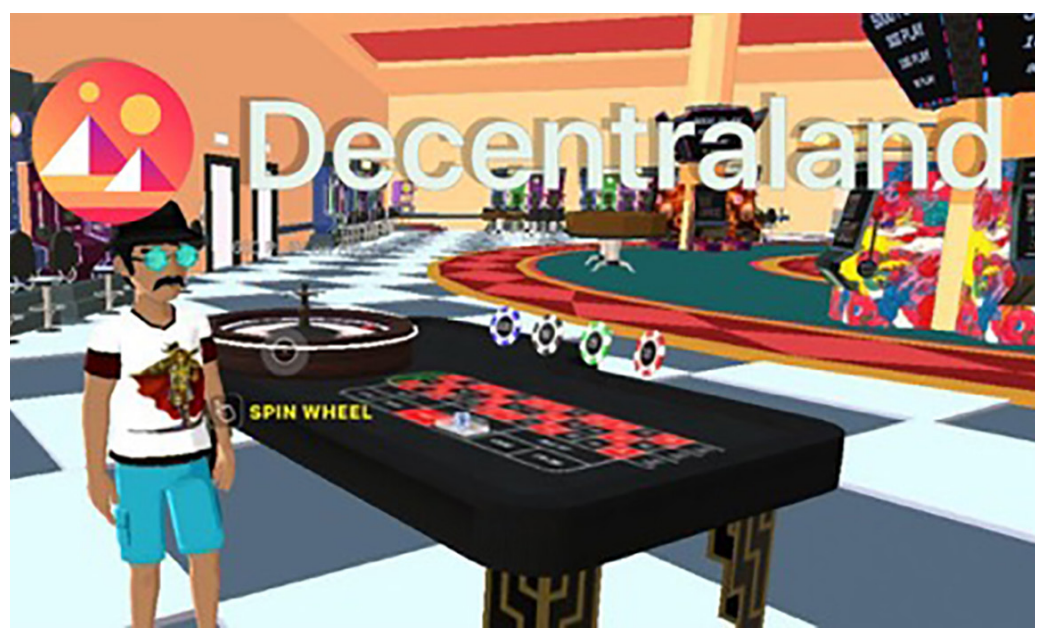

Figura 5. Noches de casino en el metauniverso de Decentraland.

Por tanto, la combinación de los espacios físicos y los virtuales es otra de las características del comportamiento de esta generación. Los espacios virtuales en modo alguno están sustituyendo a los espacios físicos, pues las técnicas virtuales permiten sumergirse en la imagen, actuar y trabajar en un universo tridimensional, compatibilizando ambos mundos. 
Bajo este punto de vista, no podría hablarse de que lo virtual y lo físico sean dos realidades incompatibles, pues contrariamente a lo interesadamente sostenido por algunos, los espacios virtuales no están pensados para un uso individual sino para la sociabilización, ejemplo de ello son las diferentes ligas de e-sports.

Las herramientas tecnológicas ofrecen a los jóvenes nuevos espacios y tiempos virtuales, que facilitan el contacto con otras realidades e interactuar con personas que no están en su entorno cercano, pudiendo desarrollar sus opiniones, prejuicios y estereotipos sobre distintas facetas de la vida.

Y quizás, en este punto es donde se visualiza una de las principales diferencias con respecto al impacto de la tecnología en la vida de las distintas generaciones, pues para los Nativos Digitales, no es posible separar la tecnología de su vida personal, ya que consideran al mundo virtual como parte esencial de su entorno natural y, por ello, tan real como el mundo físico.

\section{Activismo de contenidos}

La generación Z quiere ser parte de la conversación política, y su acceso sin fisuras a la tecnología y a todo tipo de contenidos les permite participar de una manera que ninguna generación ha tenido antes.

En el mejor sentido de la palabra, la ciudadanía se apodera de la tecnología para convertirla en una herramienta cívica. El activismo digital permite contactar, intercambiar información, participar de decisiones colectivas, influir sobre otros que están a miles de kilómetros, ser proactivos y no solo receptores, dar voz, educar y movilizar a la sociedad.

Para el activismo la expansión de las nuevas tecnologías de la información y la comunicación ha supuesto un punto de inflexión: lo ponen todo a favor para influir y cambiar sin cambiar 
de sitio. Las acciones tradicionales de protesta, manifestaciones, pegadas de carteles..., se combinan con otras que se originan en la red.

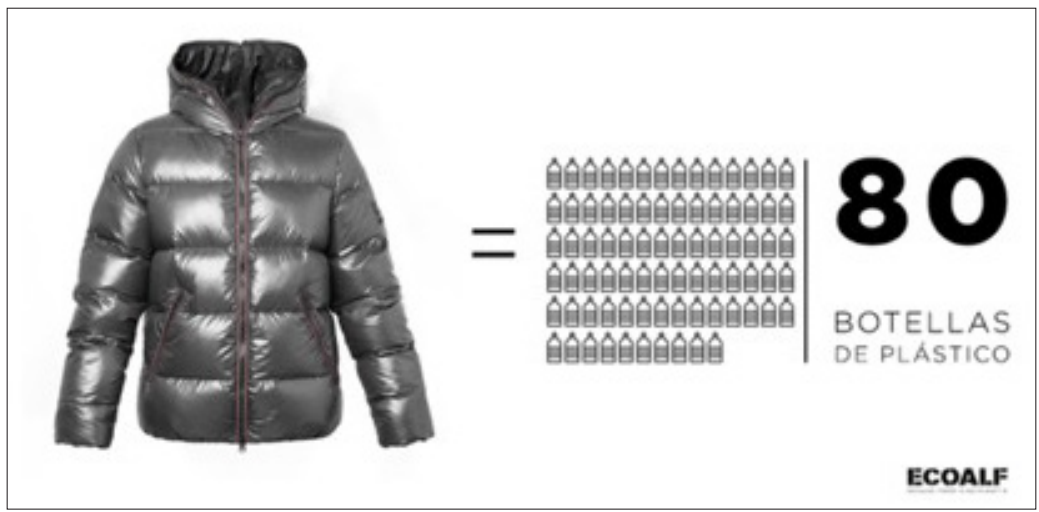

Figura 6. Ecoalf, marca española de moda que usa solamente materiales reciclados.

Fuente: https://ecoalf.com/es.

Según Spotify, la generación Z cree que cualquier persona en cualquier lugar tiene el poder de romper el statu quo de los medios sociales y convertirse en infuencer y activista social. El $72 \%$ de las personas encuestadas en 2018 dijeron que este descubrimiento impulsa su felicidad, así que para triunfar en su medio las posiciones de las empresas y de los productos frente a las causas sociales deben ser genuinas.

Un significativo 66\% de los encuestados dijeron que esperan que las marcas formen parte del debate, que promuevan los valores progresistas y que desempeñen un papel más significativo en la sociedad.

Para que este activismo de marca en su sentido integral, sea real debería lograr no solo la atracción y vinculación de las personas, sino también su movilización en torno a esa causa. 
En esta misma dirección apunta, afirmó la estrella del pop canadiense Alessia Cara, «Nuestros ojos se han abierto a la falta de liderazgo de los que están en posiciones de poder», «Y, a su vez, muchos de nosotros hemos tenido que dar un paso adelante en su lugar».

\section{Conclusión}

A modo de resumen, podemos concluir que la generación $\mathrm{Z}$ es la primera generación nativa digital, de modo que el uso de los teléfonos inteligentes esencial para sus integrantes.

Asimismo, sus gustos, relaciones y prioridades se vinculan con la información que perciben en el mundo digital.

Como consumidores, el comportamiento de la generación $Z$ refleja sus valores y la influencia de un mundo cada vez más digital. Los niños de la generación $Z$ se apoyan en sus conocimientos tecnológicos y en sus amplias redes sociales para tomar decisiones de compra informadas. Su pragmatismo les lleva a explorar y evaluar una serie de opciones antes de decidirse por un producto. Además, es más probable que se dejen influir por las recomendaciones de usuarios reales que por los avales de los famosos.

Por otra parte, se distinguen por ser creativos y les gusta aprender por sí mismos. Son combativos socialmente y críticos con las empresas e instituciones.

Los niños de la generación $Z$ también ven afectada su salud mental por la turbulenta situación del mundo. A medida que aumenta el activismo político entre la generación Z, muchos de ellos han interiorizado el malestar que rodea a cuestiones como el control de las armas, la brutalidad policial y el cambio climático, lo que ha provocado un aumento de los niveles de estrés. 
La mentalidad financiera es otra característica fundamental de la generación Z. Muchos miembros de la generación Z crecieron viendo cómo sus padres sufrían grandes golpes financieros durante la última gran recesión. Al haber sido testigos de las dificultades de sus padres, esta generación se guía por el pragmatismo y la seguridad.

Además, poseen un amplio conocimiento sobre las tendencias tecnológicas y una alta capacidad para encontrar soluciones haciendo un uso eficiente de los recursos disponibles y finalmente, La inmediatez, la necesidad ubicua del aquí y ahora es otro de los rasgos que los distingue.

Es obvio, que con este inmenso giro, como decía Alessandro Baricco en su ensayo Los Bárbaros en el que habla de las mutaciones culturales de la generación digital «El oxígeno para los bárbaros está en el acontecer de experiencias, lo anterior ya no les funcionaba, con los pulmones respiraban mal. La solución que encontraron fue ponerse branquias y aprender modelos nuevos, técnicas inéditas, y entonces volvieron a adquirir experiencias, pero ya eran peces». 